\title{
Carfilzomib Induces Drug Resistance in A2780 Ovarian Cancer Cells Through p53-Dependent and Caspase-3 Independent Pathways
}

\author{
Sadegh Zarei ${ }^{1}$, Javad Zavar Reza ${ }^{{ }^{*}}$, Hossein Zarei Jaliani ${ }^{*}$, Mohammad Reza Hajizadeh ${ }^{3}$, Saman Sargazi4 \\ ${ }^{1}$ Department of Clinical Biochemistry, School of Medicine, Shahid Sadoughi University of Medical Sciences, Yazd, Iran \\ ${ }^{2}$ Protein Engineering Laboratory, Department of Medical Genetics, School of Medicine, Shahid Sadoughi University of Medical \\ Sciences, Yazd, Iran \\ ${ }^{3}$ Molecular Medicine Research Center, Department of Biochemistry, Rafsanjan University of Medical Sciences, Rafsanjan, Iran \\ ${ }^{4}$ Cellular and Molecular Research Center, Zahedan University of Medical Sciences, Zahedan, Iran
}

Corresponding Authors: Javad Zavar Reza, PhD, Associate Professor, Department of Clinical Biochemistry, School of Medicine, Shahid Sadoughi University of Medical Sciences, Yazd, Iran. Tel: +98-3538202633, Fax: +98-3538202633, Email: Jzavar@ssu.ac.ir; Hossein Zarei Jaliani, PhD, Assistant Professor, Protein Engineering Laboratory, Department of Medical Genetics, School of Medicine, Shahid Sadoughi University of Medical Sciences, Yazd, Iran. Email: zarei.j@gmail.com

Received March 3, 2019; Accepted May 15, 2019; Online Published June 30, 2019

\begin{abstract}
Introduction: Resistance to selective small-molecule inhibitors has been a substantial factor for limiting the efficacy of ovarian cancer. Recent studies have revealed that proteasome inhibitors induce acquired drug resistance. The possible mechanisms underlying the resistance to carfilzomib (CFZ), a recently developed inhibitor of proteasome, has not been well studied. This experimental study has aimed to determine if CFZ induces drug resistance in A2780 ovarian cancer cells through p53- and caspase-3 dependent pathways.

Materials and Methods: The A2780CFZ cells were generated by continuous culturing of A2780S cells in the presence of CFZ for 4 months. The MTT cytotoxic assay was applied to compare the survival rates in A2780CFZ and A2780S cells. Also, the relative expression of $p 53$ and caspase- 3 genes were evaluated using quantitative real-time polymerase chain reaction (qRT-PCR). The nonparametric ANOVA and Friedman tests were used for data analysis.

Results: A significant difference was observed between the viability of resistant- and sensitive-A2780 cells exposed to various concentrations of CFZ, indicating that A2780S cells have become resistant to this drug under long-term culture. Compared with A2780CFZ cells, the mRNA levels of p53 gene in A2780S cells were significantly increased after $12(P=0.008)$, and 24 hours $(P=0.034)$. Also, no significant differences were observed regarding caspase-3 mRNA levels between both cell lines $(P>0.05)$.

Conclusions: The findings of this study suggest that regulation of $p 53$ gene expression in A2780CFZ cells might be the possible primary mechanism for gaining resistance against CFZ, but this might be independent of caspase cascades activation. Further studies are required to find strategies for overcoming CFZ resistance.

Keywords: Drug Resistance, Proteasome Inhibitors, Carfilzomib, Ovarian Cancer

Citation: Zarei S, Zavar Reza J, Zarei Jaliani H, Hajizadeh MR, Sargazi S. Carfilzomib induces drug resistance in A2780 ovarian cancer cells through p53-dependent and caspase-3 independent pathways. J Appl Biotechnol Rep. 2019;6(2):45-49. doi:10.29252/JABR.06.02.01.
\end{abstract}

\section{Introduction}

Among all female malignancies, ovarian cancer (OC) have the most clinical significance. ${ }^{1}$ Epithelial OC accounts for more than two-thirds of all OC cases, due to its asymptomatic manifestations before the initiation of tumor invasion. ${ }^{2-4}$ The initial standard treatments for OC are removal surgeries and chemotherapy with a combination of platinum derivatives. ${ }^{5}$ The response rate for $\mathrm{OC}$ cells to platinum derivatives is estimated at about $80 \% .^{6}$ However, the disease often reappears after 12 months, and resistance to this type of chemotherapeutic agents have usually gained afterwards, ${ }^{7}$ with only $20 \%$ to $30 \%$ of OC patients survive for 5 years after treatment with the classic platinum drugs. ${ }^{8}$

The ubiquitin/proteasome system mainly regulates protein turnover of the cell while degrading polyubiquitinated proteins. Recently, many investigations have provided a rationale regarding the link between apoptosis and the proteasome, emphasizing the key role of the proteasome in the regulation of apoptotic cell death. ${ }^{9}$ Resistance to cell-death inducing agents are mainly associated with deregulation of mitochondrial apoptosis in cancer cells ${ }^{10,11}$ and disorder in the immunological defence mechanism, ${ }^{12}$ leading to a down-regulation in cell survival suppressors (e.g., p53 and caspase-3)..$^{14,15}$ Moreover, proteasome inhibition

Copyright (C) 2019 The Author(s). This is an open-access article distributed under the terms of the Creative Commons Attribution License (http:// creativecommons.org/licenses/by/4.0), which permits unrestricted use, distribution, and reproduction in any medium, provided the original work is properly cited. 
can cause abnormalities in signal transduction, cell cycle control, transcription regulation, and inflammation. ${ }^{15,16}$ The underlined mechanisms include phosphorylation, removal of the anti-apoptotic agents, and p53 stabilization. ${ }^{17-19}$ Proteasome inhibitors have proven to be useful therapeutic small-molecule inhibitors for the treatment of multiple myeloma, and other malignancies ${ }^{20,21}$ since the proliferation of cancer cells depends on the ubiquitin-proteasome system. ${ }^{19,22}$

Carfilzomib (CFZ), a recently developed selective proteasome inhibitor, is currently approved in the United States for the treatment of relapsing/resistant multiple myeloma. ${ }^{22,23}$ Despite Bortezomib and other proteasome inhibitors, CFZ irreversibly binds to its target, leading to a stable inhibition of the enzyme $\mathrm{e}^{22-25}$ while showing less favourable side-effects and lower toxicity to non-proteases and the serum proteases. ${ }^{26}$ Bortezomib resistance was observed in some of the preclinical models, suggesting that resistance to proteasome inhibition might decrease the efficacy of anti-tumor therapy. ${ }^{27}$

It is said that p53 mediates apoptosis through different pathways due to the induction of oxidative stress or exposure to DNA damaging agents. ${ }^{28,29}$ Mutations and decreased expression of p53 have been reported in various types of human cancers, including OC..$^{30,31}$ Activation of this tumor suppressor is essential for sensitizing cancer cells to multiple anti-tumor agents. ${ }^{32}$ Accordingly, the inactivation and downregulation of the $p 53$ gene in OC cells can lead to resistance to classic platinum drugs. ${ }^{33,34}$ Also, some studies have reported that proteasome inhibitors trigger apoptosis via both $p 53$ dependent and -independent pathways. ${ }^{35,36}$ Chen et al explored the efficacy of inhibitors of the $26 \mathrm{~S}$ proteasome on the induction of cell death in the human colon cancer cells differing in their p53 status, discovering that targeting of proteasome inhibitors might cause nuclear accumulation of p53 as cells with inactive $p 53$ showed an attenuated apoptosis rate after treatment with these types of selective inhibitors. ${ }^{37}$

On the other hand, the anticancer effects caused by various anti-tumor agents are followed by the activation of at least one component of the caspase family. ${ }^{38}$ Caspase- 3 is a critical enzyme involved in both intrinsic and extrinsic apoptotic signaling pathways, as well as an effector in celldeath induction by proteasome inhibitors. Caspase activation results in the cleavage of the $19 \mathrm{~S}$ regulatory complex of the proteasome subunits. ${ }^{39}$ This cleavage mediated by caspases suppresses the proteasomal degradation of polyubiquitinated proteins within the cell. ${ }^{9,40}$

One promising approach towards overcoming cell-death resistance is to employ molecular targeted cancer therapies since selective inhibition of proteasome triggers cell-death in tumor cells, but not in the normal cells. Hence, this experimental investigation is aimed to determine if CFZ induces drug resistance in A2780 OC cells through p53- and caspase- 3 dependent pathways by evaluating the mRNA levels of these genes.

\section{Materials and Methods}

Carfilzomib was purchased from AdooQ BioScience (CA, USA) at a concentration of $200 \mu \mathrm{g} / \mathrm{mL}$ in dissolved dimethyl sulfoxide (DMSO) and was stored at $-20^{\circ} \mathrm{C}$. Also, the MTT
[3-(4, 5-dimethylthiazol-2-yl)-2, 5-diphenyltetrazolium bromide] dye was supplied by Sigma-Aldrich (USA).

\section{Cell Culture}

Human ovarian cancer cell line A2780 was purchased from the Pastor Institute (Tehran, Iran) and grown in Roswell Park Memorial Institute medium 1640 (RPMI 1640) supplemented with $10 \%$ FBS (Gibco, CA, USA), 100 units/mL of penicillin, and $100 \mathrm{~g} / \mathrm{mL}$ of streptomycin (Gibco, CA, USA) under standard cell culture conditions (humidified atmosphere, $37^{\circ} \mathrm{C}$ with $5 \% \mathrm{CO}_{2}$ ).

\section{Resistance to Carfilzomib}

The A2780S cells were maintained with stepwise increasing concentrations of CFZ for 4 months. Initial concentrations of CFZ were $0.1 \mu \mathrm{g} / \mathrm{mL}$ over this period. ${ }^{41}$ The cells gaining resistance against CFZ were termed A2780CFZ.

\section{Cell Viability Assay}

The MTT assay was done to test the in vitro cytotoxicity of CFZ against A2780S and A2780CFZ tumor cells. The A2780S and A2780CFZ cells were seeded into 96-well plates at a concentration of approximately 10000 cells/well in three replicates. Following overnight incubation, cells were exposed to various concentrations of CFZ $(0-4 \mu \mathrm{g} / \mathrm{mL})$ for 24 hours. Later, $20 \mu \mathrm{L}$ MTT dye $(5 \mathrm{mg} / \mathrm{mL})$ was placed into each well and incubated for 4 hours. Absorbance was read at $490 \mathrm{~nm}$ with $630 \mathrm{~nm}$ as the wavelength reference. The half maximal inhibitory concentration (IC50) values were measured using GraphPad Prism 6.0 (CA, USA).

\section{Quantitative Real-Time Polymerase Chain Reaction}

Following cell seeding in 6-well-microplates $(250000$ cells/ well), total RNAs was isolated from A2780S and A2780CFZ cells. Next, cDNA was synthesised using the cDNA synthesis kit (Sinaclon, Tehran, Iran). For quantitative real-time polymerase chain reaction (RT-PCR) analysis of $p 53$ and Caspase 3 transcripts, the primer sequences were: for $p 53$, sense 5'-GTCCCAGGAGCCCATCCT-3' and antisense 5'-CCCGGCTGTTGTCTCCAT-3'; for Caspase3, sense 5'-CATGGCTCAGAAGCACACAAAC-3' and antisense 5'-CTCGGTCTGGTACAGATGTCGA-3'; for GAPDH, sense 5'-CTCATTTCCTGGTATGACAACGA- $3^{\prime}$ and antisense 5'-TCTTCCTCTTGTGCTCTTGCTG-3'. The PCR reactions were performed using Rotor-Gene ${ }^{\mathrm{TM}} 6000$ Real-time Analyzer with the SYBR Green qPCR Mastermix (Yekta Tajhiz Azma, Iran). The PCR program began with an initial denaturation at $96{ }^{\circ} \mathrm{C}$ for 10 minutes, 40 cycles of annealing (at $65{ }^{\circ} \mathrm{C}$ for $p 53$ or $G A P D H$, and $55^{\circ} \mathrm{C}$ for Caspase3) followed by an extension at $72^{\circ} \mathrm{C}$ for 45 seconds. The relative quantity of the transcripts was evaluated using the $2^{-\Delta \Delta \mathrm{Ct}}$ methods. ${ }^{42}$

\section{Statistical Analysis}

Results were expressed as Mean \pm SD where applicable. The SPSS 22 software was used for the data analysis. Unpaired Student's $t$ test and non-parametric ANOVA test were employed to determine statistic probabilities $(P<0.05)$. 


\section{Results}

In Vitro Cytotoxicity

As presented in Figure 1, the growth inhibitory effects of CFZ when both A2780S and A2780CFZ cells were treated with the mentioned concentrations of this agent for 24 hours. The IC50 values were measured at $0.15 \mu \mathrm{g} / \mathrm{mL}$ (for A2780S cells) and $7.21 \mu \mathrm{g} / \mathrm{mL}$ (for A2780CFZ cells), indicating that A2780S cells had become resistant to CFZ after long exposure. However, this novel proteasome inhibitor was able to induce significant cell-death following a concentration-dependent pattern of A2780S cells, compared to adjusted untreated cells.

Effects of Carfilzomib on p53 and Caspase 3 mRNA Levels

As shown in Figure 2, CFZ was increased the mRNA levels of the $p 53$ gene following 6 hours (1.1 fold of the control in A2780S cells and 1.95 fold in A2780CFZ cells, $P=0.12$ ), 12 hours (4.02 fold of the control in A2780S cells and 1.22 fold in A2780CFZ cells, $P=0.005$ ), and 24 hours (2.72 fold of the control in A2780S cells and 0.8 fold in A2780CSZ cells, $P=0.041)$ compared to the untreated cells. Also, significant differences were noticed between $p 53$ mRNA levels of both cells after 12 hours $(P=0.008)$ and 24 hours $(P=0.034)$, showing that this proteasome inhibitor up-regulates $p 53$ expression in both cells but significantly in A2780s cells. Regarding Caspase3 mRNA levels, significant increases were observed following 6 hours (3.80 fold of the control in A2780S cells and 3.51 fold in A2780CFZ cells, $P=0.006)$ and 12 hours ( 1.95 fold of the control in A2780S cells and 2.23 fold in A2780CFZ cells, $P=0.041)$. Moreover, no statistical differences were observed in this regard by comparing both cells in all incubation times $(P>0.05)$.

\section{Discussion}

Tumor cells are profoundly dependent on proteasomeregulated homeostatic mechanisms. ${ }^{43}$ Proteasome inhibitors have antitumor activity. ${ }^{44}$ Although various cellular targets were correlated with bortezomib-induced apoptotic cell death, ${ }^{40-42}$ the exact molecular target of CFZ remained unclear. The CFZ consists of an epoxyketone pharmacophore, specifically bind to the terminal threonine residue and catalyzes enzymatic activity within the proteasome. ${ }^{25,45}$

To the best of the researcher's knowledge, this is the first study which has aimed to determine the mechanisms responsible for CFZ resistance. According to the results of this research, A2780 OC cells gained resistance against CFZ after 4 months of exposure, verified by MTT assay. It is suggested that acquiring this resistance might lead to significant changes in the expression of both $p 53$ and caspase 3 genes.

Regarding p53 gene, no significant changes were found in mRNA levels of both sensitive- and resistant-A2780 cells following 6 hours (compared with the adjusted untreated cells), while this gene was significantly up-regulated at 12 and 24 hours in A2780S cells. These findings suggest that the p53 pathway might be a crucial modulator of cell-death in A2780CFZ cells since these cells showed higher proliferative rates while no changes were noticed in the mRNA levels of this tumor suppressor from 0 to 24 hours. Caspase 3 gene

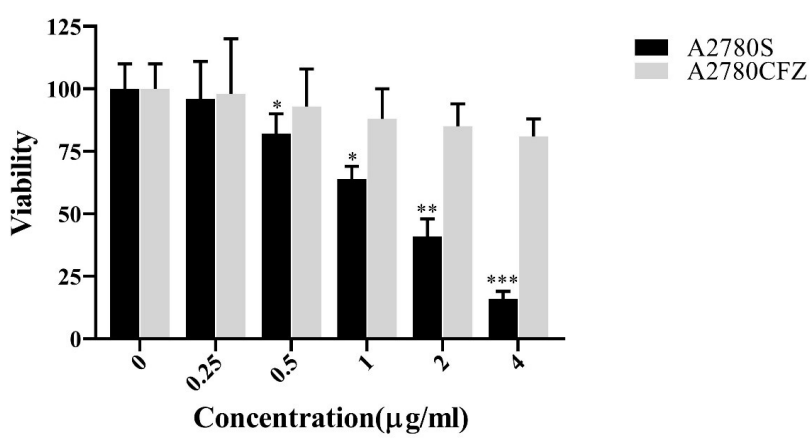

Figure 1. MTT Absorbance Related to the CFZ Concentration (between 0 to 4 $\mu \mathrm{g} / \mathrm{mL}$ ). This method was repeated at least three times, and data are expressed as mean \pm standard deviation (SD). The measured IC50 values indicates that A2780S cells gained resistance against CFZ following 4 months of exposure ( ${ }^{*} P$ $<0.05,{ }^{* *} P<0.01$, and ${ }^{* * *} P<0.001$ vs control cells).
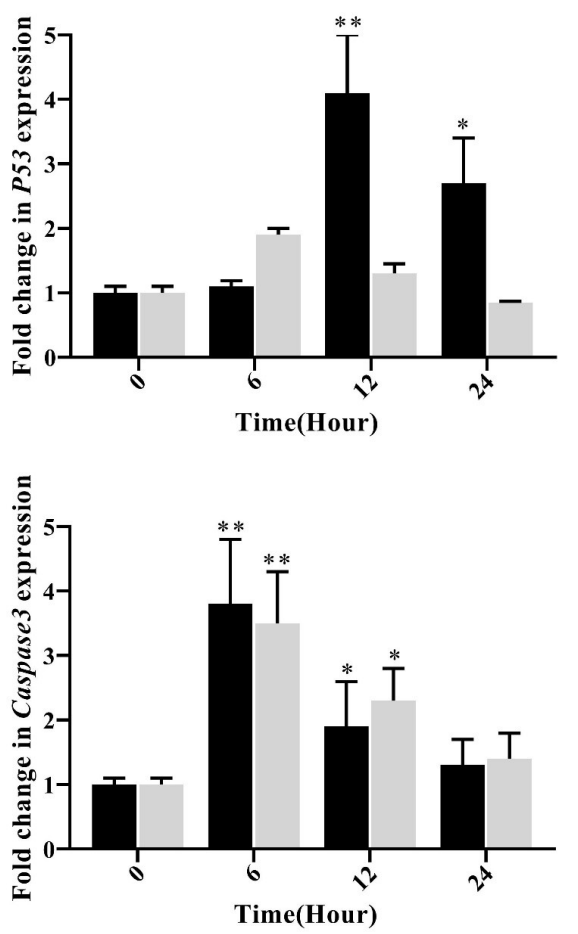

Figure 2. Gene Expression Analysis of $p 53$ and Caspase 3 following 0 to $24 \mathrm{~h}$ in Both Cell Lines Exposed to CFZ With Concentrations Equal to Their IC50 Values. Expression levels were normalized to GAPDH mRNA levels assessed with the same technique $\left(* P<0.05\right.$ and ${ }^{* *} P<0.01$ vs controls).

expression followed a different pattern. Following 6 and 12 hours, the caspase 3 mRNA levels were significantly increased in both cells (compared with control cells) where it returned to its basal levels after 24 hours. Since no significant differences were observed in the levels of caspase 3 mRNAs in A2780S cells compared with A2780CFZ cells, it is proposed that acquiring CFZ-resistance might be through caspaseindependent pathways.

Hideshima et al reported that the PS-341, a dipeptide boronic acid analogue, effectively suppresses the proliferation 
of human multiple myeloma cells by inducing apoptosis, thus overcoming drug resistance. ${ }^{49}$ Frankel and colleagues analyzed the activity of PS-341 in human prostate and OC cell lines, discovering that PS-341 overcomes multi-cellular drug resistance by triggering apoptosis via decreasing a protein member of the IAP (inhibitor of apoptosis) family and enhancement of Bcl- $\mathrm{X}_{\mathrm{L}}$ phosphorylation. ${ }^{50}$ No similar study has been conducted to assess if different tumor cells acquire resistance against PS-341 while highlighting the involved pathways. Oerlemans et al announced that clinical efficacy of Bortezomib had been hampered in human myelomonocytic THP1 cells due to drug-resistance phenomena, proposing that overexpression of PSMB5 ( $\beta 5$-subunit of proteasome) gene and protein might have a role in the development of drug resistance. ${ }^{51}$ However, CFZ displays much higher specificity for the chymotrypsin-like activity at the $\beta 5$-subunit compared to the other proteasome inhibitors. ${ }^{27}$ Rajkumar et al suggested that the blocked degradation of the polyubiquitinated proteins such as negative regulators of the nuclear factor (NF)- $\kappa \mathrm{B}$ pathway could be responsible for the cells unresponsiveness to bortezomib. Also, the possible increases in gene and protein expression involved in cell survival and apoptotic/ antiapoptotic pathways can confer cancer cells to proteasome inhibitors resistance. ${ }^{52}$ In contrast to the findings of this study, Ling et al highlighted the sensitivity of the p53-proficient tumor cells to bortezomib treatment while p53-deficient tumor cells were resistant to bortezomib-mediated cell death.

Up to this date, the underlying resistance mechanisms of proteasome inhibitors has remained controversial. In this study, it was sought to discover if p53 and caspase3-dependent pathways are involved in gaining resistance against CFZ as an epoxomicin-related proteasome inhibitor. The present study faced some limitations. The determination of protein levels of p53 and caspase 3 besides the evaluation of caspase 3 enzymatic activity could be done in order to confirm the results of this study.

\section{Conclusions}

The results of this research, for the first time, explained the possible mechanisms underlying CFZ resistance in OC cells and linked the effect of resistance to this irreversible inhibitor of the ubiquitin-proteasome pathway in association with p53 gene expression, which might be dependent to the type of cancer. Further studies on other cells may indicate the precise pathways involved in the development of the resistance against proteasome inhibitors.

\section{Authors' Contributions}

SZ, JZR and HZJ designed the study. SZ and SS performed the experiments (e.g. cell cultures, expressed all genes). MRH analyzed the data. SZ and SS wrote the paper with input from all authors. All authors provided critical feedback and approved the final version of the manuscript.

\section{Conflict of Interest Disclosures}

The authors declare they have no conflicts of interest.

\section{Acknowledgments}

This study was supported by Shahid Sadoughi University of Medical
Sciences, Yazd, Iran. The authors would like to thank colleagues for their kind and generous assistance.

\section{References}

1. Tiwari A, Hadley JA, Hendricks GL 3rd, Elkin RG, Cooper T, Ramachandran R. Characterization of ascites-derived ovarian tumor cells from spontaneously occurring ovarian tumors of the chicken: evidence for E-cadherin upregulation. PLoS One. 2013;8(2):e57582. doi:10.1371/journal.pone.0057582.

2. Zhao H, Yang Z, Wang X, et al. Triptolide inhibits ovarian cancer cell invasion by repression of matrix metalloproteinase 7 and 19 and upregulation of E-cadherin. Exp Mol Med. 2012;44(11):633641. doi:10.3858/emm.2012.44.11.072.

3. Reid BM, Permuth JB, Sellers TA. Epidemiology of ovarian cancer: a review. Cancer Biol Med. 2017;14(1):9-32. doi:10.20892/j. issn.2095-3941.2016.0084.

4. Torre LA, Trabert B, DeSantis CE, et al. Ovarian cancer statistics, 2018. CA Cancer J Clin. 2018;68(4):284-296. doi:10.3322/ caac. 21456.

5. Armstrong DK, Bundy B, Wenzel L, et al. Intraperitoneal cisplatin and paclitaxel in ovarian cancer. N Engl J Med. 2006;354(1):3443. doi:10.1056/NEJMoa052985.

6. Berry NB, Bapat SA. Ovarian cancer plasticity and epigenomics in the acquisition of a stem-like phenotype. J Ovarian Res. 2008;1:8. doi:10.1186/1757-2215-1-8.

7. Ozols R. Treatment of gynecologic cancer: the US experience. Tumori. 1999;85(3 Suppl 1):S5-11. doi:10.1159/000015273.

8. Matulonis UA, Sood AK, Fallowfield L, Howitt BE, Sehouli J, Karlan BY. Ovarian cancer. Nat Rev Dis Primers. 2016;2:16061. doi:10.1038/nrdp.2016.61.

9. Sun XM, Butterworth M, MacFarlane M, Dubiel W, Ciechanover A, Cohen GM. Caspase activation inhibits proteasome function during apoptosis. Mol Cell. 2004;14(1):81-93. doi:10.1016/ S1097-2765(04)00156-X.

10. Miyamoto M, Takano M, Iwaya K, et al. X-chromosome-linked inhibitor of apoptosis as a key factor for chemoresistance in clear cell carcinoma of the ovary. Br J Cancer. 2014;110(12):28812886. doi:10.1038/bjc.2014.255.

11. Roodhart JM, Daenen LG, Stigter EC, et al. Mesenchymal stem cells induce resistance to chemotherapy through the release of platinum-induced fatty acids. Cancer Cell. 2011;20(3):370-383. doi:10.1016/j.ccr.2011.08.010.

12. Woo MG, Xue K, Liu J, McBride H, Tsang BK. Calpain-mediated processing of p53-associated parkin-like cytoplasmic protein (PARC) affects chemosensitivity of human ovarian cancer cells by promoting p53 subcellular trafficking. J Biol Chem. 2012;287(6):3963-3975. doi:10.1074/jbc.M111.314765.

13. Petitjean A, Mathe E, Kato S, et al. Impact of mutant p53 functional properties on TP53 mutation patterns and tumor phenotype: lessons from recent developments in the IARC TP53 database. Hum Mutat. 2007;28(6):622-629. doi:10.1002/humu.20495.

14. Abedini MR, Muller EJ, Bergeron R, Gray DA, Tsang BK. Akt promotes chemoresistance in human ovarian cancer cells by modulating cisplatin-induced, p53-dependent ubiquitination of FLICE-like inhibitory protein. Oncogene. 2010;29(1):11-25. doi:10.1038/onc.2009.300.

15. Moore BS, Eustaquio AS, McGlinchey RP. Advances in and applications of proteasome inhibitors. Curr Opin Chem Biol. 2008;12(4):434-440. doi:10.1016/j.cbpa.2008.06.033.

16. Weyburne ES, Wilkins OM, Sha Z, et al. Inhibition of the proteasome $\beta 2$ site sensitizes triple-negative breast cancer cells to beta5 inhibitors and suppresses Nrf1 activation. Cell Chem Biol. 2017;24(2):218-230. doi:10.1016/j.chembiol.2016.12.016.

17. Hoeller D, Dikic I. Targeting the ubiquitin system in cancer therapy. Nature.2009;458(7237):438-444.doi:10.1038/nature07960.

18. Ludwig H, Khayat D, Giaccone G, Facon T. Proteasome inhibition and its clinical prospects in the treatment of hematologic and solid 
malignancies. Cancer. 2005;104(9):1794-1807. doi:10.1002/ cncr.21414.

19. Solomon H, Brauning B, Fainer I, et al. Post-translational regulation of p53 function through 205 proteasome-mediated cleavage. Cell Death Differ. 2017;24(12):2187-2198. doi:10.1038/ cdd.2017.139.

20. Hideshima T, Richardson P, Chauhan D, et al. The proteasome inhibitor PS-341 inhibits growth, induces apoptosis, and overcomes drug resistance in human multiple myeloma cells. Cancer Res. 2001;61(7):3071-3076.

21. O'Connor OA, Wright J, Moskowitz C, et al. Phase II clinical experience with the novel proteasome inhibitor bortezomib in patients with indolent non-Hodgkin's lymphoma and mantle cell lymphoma. J Clin Oncol. 2005;23(4):676-684. doi:10.1200/ jco.2005.02.050.

22. Bennett MK, Kirk CJ. Development of proteasome inhibitors in oncology and autoimmune diseases. Curr Opin Drug Discov Devel. 2008;11(5):616-625.

23. Demo SD, Kirk CJ, Aujay MA, et al. Antitumor activity of PR171, a novel irreversible inhibitor of the proteasome. Cancer Res. 2007;67(13):6383-6391. doi:10.1158/0008-5472.can-06-4086.

24. Kuhn DJ, Chen Q, Voorhees PM, et al. Potent activity of carfilzomib, a novel, irreversible inhibitor of the ubiquitin-proteasome pathway, against preclinical models of multiple myeloma. Blood. 2007;110(9):3281-3290. doi:10.1182/blood-2007-01-065888.

25. Huber EM, Heinemeyer W, Li X, Arendt CS, Hochstrasser M, Groll M. A unified mechanism for proteolysis and autocatalytic activation in the $20 S$ proteasome. Nat Commun. 2016;7:10900. doi:10.1038/ncomms10900.

26. Arastu-Kapur S, Anderl JL, Kraus M, et al. Nonproteasomal targets of the proteasome inhibitors bortezomib and carfilzomib: a link to clinical adverse events. Clin Cancer Res. 2011;17(9):2734-2743. doi:10.1158/1078-0432.ccr-10-1950.

27. Lu S, Wang J. The resistance mechanisms of proteasome inhibitor bortezomib. Biomark Res. 2013;1(1):13. doi:10.1186/2050-7771$1-13$.

28. Meek DW. Tumour suppression by p53: a role for the DNA damage response? Nat Rev Cancer. 2009;9(10):714-723. doi:10.1038/ $\operatorname{nrc2716.}$

29. Aubrey BJ, Kelly GL, Janic A, Herold MJ, Strasser A. How does p53 induce apoptosis and how does this relate to p53-mediated tumour suppression? Cell Death Differ. 2018;25(1):104-113. doi:10.1038/cdd.2017.169.

30. Bykov VJN, Eriksson SE, Bianchi J, Wiman KG. Targeting mutant p53 for efficient cancer therapy. Nat Rev Cancer. 2018;18(2):89102. doi:10.1038/nrc.2017.109.

31. Parrales A, Iwakuma T. Targeting Oncogenic Mutant p53 for Cancer Therapy. FrontOncol. 2015;5:288. doi:10.3389/fonc.2015.00288.

32. Leijen S, Beijnen JH, Schellens JHM. Abrogation of the G2 checkpoint by inhibition of Wee-1 kinase results in sensitization of p53-deficient tumor cells to DNAdamaging agents. Curr Clin Pharmacol. 2010;5(3):186-191. doi:10.2174/157488410791498824.

33. Buttitta F, Marchetti A, Gadducci A, et al. p53 alterations are predictive of chemoresistance and aggressiveness in ovarian carcinomas: a molecular and immunohistochemical study. $\mathrm{Br}$ J Cancer. 1997;75(2):230-235. doi:10.1038/bjc.1997.38.

34. Hientz K, Mohr A, Bhakta-Guha D, Efferth T. The role of p53 in cancer drug resistance and targeted chemotherapy. Oncotarget. 2017;8(5):8921-8946. doi:10.18632/oncotarget.13475.

35. Perez-Galan P, Roue G, Villamor N, Montserrat E, Campo E, Colomer D. The proteasome inhibitor bortezomib induces apoptosis in mantle-cell lymphoma through generation of ROS and Noxa activation independent of p53 status. Blood. 2006;107(1):257-264. doi:10.1182/blood-2005-05-2091.

36. Saini H, Hakeem I, Mukherjee S, Chowdhury S, Chowdhury R.
Autophagy Regulated by Gain of Function Mutant p53 Enhances Proteasomal Inhibitor-Mediated Cell Death through Induction of ROS and ERK in Lung Cancer Cells. J Oncol. 2019;2019:6164807. doi:10.1155/2019/6164807.

37. Chen F, Chang D, Goh M, Klibanov SA, Ljungman M. Role of p53 in cell cycle regulation and apoptosis following exposure to proteasome inhibitors. Cell Growth Differ. 2000;11(5):239-246.

38. Cullen SP, Martin SJ. Caspase activation pathways: some recent progress. Cell Death Differ. 2009;16(7):935-938. doi:10.1038/ cdd.2009.59.

39. Cohen GM. Caspase inactivation of the proteasome. Cell Death Differ. 2005;12(9):1218. doi:10.1038/sj.cdd.4401693.

40. Qiang YW, Ye S, Huang Y, et al. MAFb protein confers intrinsic resistance to proteasome inhibitors in multiple myeloma. BMC Cancer. 2018;18(1):724. doi:10.1186/s12885-018-4602-4.

41. Ao L, Wu Y, Kim D, et al. Development of peptide-based reversing agents for p-glycoprotein-mediated resistance to carfilzomib. Mol Pharm. 2012;9(8):2197-2205. doi:10.1021/mp300044b.

42. Livak KJ, Schmittgen TD. Analysis of relative gene expression data using real-time quantitative PCR and the 2(-Delta Delta C(T)) Method. Methods. 2001;25(4):402-408. doi:10.1006/ meth.2001.1262.

43. O'Connor OA, Stewart AK, Vallone M, et al. A phase 1 dose escalation study of the safety and pharmacokinetics of the novel proteasome inhibitor carfilzomib (PR-171) in patients with hematologic malignancies. Clin Cancer Res. 2009;15(22):70857091. doi:10.1158/1078-0432.ccr-09-0822.

44. Nencioni A, Grunebach F, Patrone F, Ballestrero A, Brossart P. Proteasome inhibitors: antitumor effects and beyond. Leukemia. 2007;21(1):30-36. doi:10.1038/sj.leu.2404444.

45. Georgakis GV, Li Y, Humphreys R, et al. Activity of selective fully human agonistic antibodies to the TRAIL death receptors TRAIL-R1 and TRAIL-R2 in primary and cultured lymphoma cells: induction of apoptosis and enhancement of doxorubicin- and bortezomibinduced cell death. $\mathrm{Br} J$ Haematol. 2005;130(4):501-510. doi:10.1111/j.1365-2141.2005.05656.x.

46. Carew JS, Giles FJ, Nawrocki ST. Histone deacetylase inhibitors: mechanisms of cell death and promise in combination cancer therapy. Cancer Lett. 2008;269(1):7-17. doi:10.1016/j. canlet.2008.03.037.

47. Strauss SJ, Higginbottom K, Juliger $S$, et al. The proteasome inhibitor bortezomib acts independently of p53 and induces cell death via apoptosis and mitotic catastrophe in B-cell lymphoma cell lines. Cancer Res. 2007;67(6):2783-2790. doi:10.1158/00085472.can-06-3254.

48. Groll M, Kim KB, Kairies N, Huber R, Crews CM. Crystal structure of epoxomicin: $20 S$ proteasome reveals a molecular basis for selectivity of $\alpha^{\prime}, \beta$ '-epoxyketone proteasome inhibitors. J Am Chem Soc. 2000;122(6):1237-1238. doi:10.1021/ja993588m.

49. Hideshima T, Richardson P, Chauhan D, et al. The proteasome inhibitor PS-341 inhibits growth, induces apoptosis, and overcomes drug resistance in human multiple myeloma cells. Cancer Res. 2001;61(7):3071-3076.

50. Frankel A, Man S, Elliott P, Adams J, Kerbel RS. Lack of multicellular drug resistance observed in human ovarian and prostate carcinoma treated with the proteasome inhibitor PS-341. Clin Cancer Res. 2000;6(9):3719-3728.

51. Oerlemans R, Franke NE, Assaraf YG, et al. Molecular basis of bortezomib resistance: proteasome subunit beta5 (PSMB5) gene mutation and overexpression of PSMB5 protein. Blood. 2008;112(6):2489-2499. doi:10.1182/blood-2007-08-104950.

52. Rajkumar SV, Richardson PG, Hideshima T, Anderson KC. Proteasome inhibition as a novel therapeutic target in human cancer. J Clin Oncol. 2005;23(3):630-639. doi:10.1200/ jco.2005.11.030. 